DOI: $10.1002 / \mathrm{ccd} .28616$

\title{
Outcomes with retrograde versus antegrade chronic total occlusion revascularization
}

\author{
Michael Megaly MD, MS ${ }^{1,2}$ (D) | Abdelrahman Ali MD M $^{3}$ Marwan Saad MD, PhD ${ }^{4,5}$ (i) |

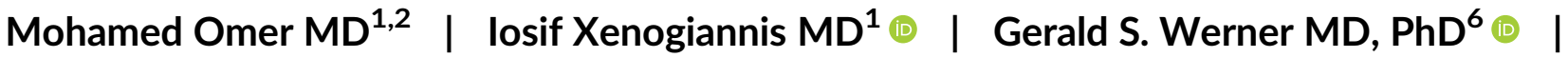 \\ Dimitri Karmpaliotis MD, PhD ${ }^{7}$ Juan J. Russo MD ${ }^{7}$ | Masahisa Yamane MD $^{8}$ | \\ Roberto Garbo MD ${ }^{9}$ | Andrea Gagnor MD ${ }^{10}$ | Imre Ungi MD, PhD ${ }^{11}$ |

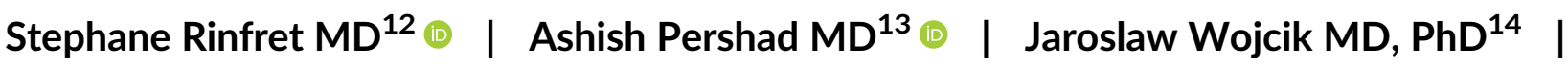 \\ Santiago Garcia MD ${ }^{1}$ (1) | Kambis Mashayekhi MD ${ }^{15}$ | Georgios Sianos MD, PhD $^{16}$ | \\ Alfredo R. Galassi MD ${ }^{17}$ | M. Nicholas Burke MD ${ }^{1}$ Emmanouil S. Brilakis MD, PhD ${ }^{1} \odot$ \\ ${ }^{1}$ Minneapolis Heart Institute, Abbott Northwestern Hospital, Minneapolis, Minnesota \\ ${ }^{2}$ Department of Cardiovascular Medicine, Hennepin Healthcare, Minneapolis, Minnesota \\ ${ }^{3}$ Department of Medicine, Mercy Hospital and Medical Center, Chicago, Illinois \\ ${ }^{4}$ Division of Cardiovascular Medicine, The Warren Alpert School of Medicine at Brown University, Providence, Rhode Island \\ ${ }^{5}$ Department of Cardiovascular Medicine, Ain Shams University Hospitals, Cairo, Egypt \\ ${ }^{6}$ Medizinische Klinik I (Cardiology and Intensive Care), Klinikum Darmstadt GmbH, Darmstadt, Germany \\ ${ }^{7}$ Department of Cardiology, Columbia University, New York, New York \\ ${ }^{8}$ Department of Cardiology, Sayama Hospital, Saitama, Japan \\ ${ }^{9}$ Department of Invasive Cardiology, San Giovanni Bosco Hospital, Turin, Italy \\ ${ }^{10}$ Department of Invasive Cardiology, Maria Vittoria Hospital, Turin, Italy \\ ${ }^{11}$ Division of Invasive Cardiology, University of Szeged, Second Department of Internal Medicine and Cardiology Center, Szeged, Hungary \\ ${ }^{12}$ Division of Interventional Cardiology, McGill University Health Centre, Montreal, Canada \\ ${ }^{13}$ Division of Cardiology, Banner-University Medical Center, Phoenix, Arizona \\ ${ }^{14}$ Department of Cardiology, Hospital of Invasive Cardiology IKARDIA, Nałęczów, Poland \\ ${ }^{15}$ Division of Cardiology and Angiology II, University Heart Center Freiburg-Bad Krozingen, Bad Krozingen, Germany \\ ${ }^{16}$ First Department of Cardiology, AHEPA University Hospital, Thessaloniki, Greece \\ ${ }^{17}$ Department of Clinical and Experimental Medicine, Catheterization Laboratory and Cardiovascular Interventional Unit, Cannizzaro Hospital, University of Catania, \\ Catania, Italy
}

Correspondence

Emmanouil S. Brilakis, MD, PhD, Minneapolis Heart Institute and Minneapolis Heart Institute Foundation, Abbott Northwestern Hospital, 920 E 28th Street \#300, Minneapolis, MN 55407.

Email: esbrilakis@gmail.com

\begin{abstract}
Objectives: The aim of the study was to evaluate the outcomes of retrograde versus antegrade approach in chronic total occlusion (CTO) percutaneous coronary intervention (PCI).

Background: The retrograde approach has increased the success rate of CTO PCI but has been associated with a higher risk for complications.

Methods: We conducted a meta-analysis of studies published between 2000 and August 2019 comparing the in-hospital and long-term outcomes with retrograde versus antegrade CTO PCI.
\end{abstract}


Results: Twelve observational studies (10,240 patients) met our inclusion criteria (retrograde approach 2,789 patients, antegrade approach 7,451 patients). Lesions treated with the retrograde approach had higher J-CTO score (2.8 vs. 1.9, $p<.001)$. Retrograde CTO PCl was associated with a lower success rate $(80.9 \%$ vs. $87.4 \%, p<.001)$. Both approaches had similar in-hospital mortality, urgent revascularization, and cerebrovascular events. Retrograde CTO $\mathrm{PCl}$ was associated with higher risk of inhospital myocardial infarction (MI; odds ratio [OR] 2.37, 95\% confidence intervals [Cl] 1.7, 3.32, $p<.001$ ), urgent pericardiocentesis (OR 2.53, 95\% Cl 1.41-4.51, $p=.002$ ), and contrast-induced nephropathy (OR 2.12, 95\% Cl 1.47-3.08; $p<.001$ ). During a mean follow-up of $48 \pm 31$ months retrograde crossing had similar mortality (OR 1.79, 95\% Cl 0.84-3.81, $p=.13$ ), but a higher incidence of MI (OR 2.07, 95\% Cl 1.1-3.88, $p=.02$ ), target vessel revascularization (OR 1.92, 95\% Cl 1.49-2.46, $p<.001$ ), and target lesion revascularization (OR 2.08, 95\% Cl 1.33-3.28, $p=.001$ ). Conclusions: Compared with antegrade CTO PCl, retrograde CTO PCl is performed in more complex lesions and is associated with a higher risk for acute and long-term adverse events.

\section{KEYWORDS}

antegrade, chronic total occlusion, outcomes, percutaneous coronary intervention, retrograde

\section{1 | INTRODUCTION}

Coronary chronic total occlusion (СTO) percutaneous coronary interventions $(\mathrm{PCl})$ can be challenging with failure to cross being the main cause of failure. The introduction of retrograde СTO crossing techniques was instrumental in increasing CTO $\mathrm{PCl}$ success rates from $<70 \%{ }^{1,2}$ to nearly $90 \% .^{3-5}$ Some, but not all, ${ }^{6,7}$ studies have reported that the retrograde approach is associated with longer procedural time, increased use of contrast and fluoroscopy, and higher incidence of periprocedural and possibly long-term adverse cardiac events. ${ }^{4,8-17}$ We performed a systematic review and a meta-analysis of in-hospital and long-term outcomes with retrograde as compared with antegrade CTO PCI.

\section{2 | METHODS}

\section{1 | Literature search}

The current meta-analysis was conducted and reported according to the proposal for conducting and reporting Meta-analyses of observational studies (MOOSE) ${ }^{18}$ and is registered with the International Prospective Register for Systematic Reviews (PROSPERO: CRD42019124763). We performed a systematic computerized search of the EMBASE, Cochrane, and MEDLINE databases from 2000 to August 2019 using the following search terms separately and in combination; "chronic total occlusion," "CTO," "CTO PCI," "retrograde," "antegrade," and "revascularization." We screened the bibliographies of the retrieved studies for relevant studies not retrieved through the initial search. Our search was limited to the English language. Abstracts and review papers were not included in this study.

\subsection{Study selection}

We included published studies that compared the outcomes with retrograde versus antegrade approaches in СTO $\mathrm{PCl}$. If more than one study reported outcomes of the same cohort of patients, we included the most recent or most comprehensive publication. For long-term outcomes, we included studies with a minimum of 12 months follow-up.

\subsection{Data extraction and quality assessment}

The data were abstracted by two independent investigators (AA, MS) and adjudicated by a third investigator (MM); all the investigators are physicians. Discrepancies were settled by consensus. The risk of bias of the included studies was assessed using the Newcastle-Ottawa Scale for observational studies. ${ }^{19}$

\section{4 | Study end-points}

Primary endpoints were in-hospital mortality, myocardial infarction (MI), need for urgent revascularization, need for urgent pericardiocentesis, contrast-induced nephropathy, procedural success, procedural time, fluoroscopy time, and contrast volume. Secondary endpoints included long-term outcomes: all-cause mortality, MI, target 
lesion revascularization (TLR), and target vessel revascularization (TVR). The definitions of outcomes, according to each included study are described in Table S1. Long-term outcomes were reported at the longest follow-up time available. For this analysis, the total number of lesions was utilized for procedural success while the total number of patients was used for clinical outcomes. One study reported baseline characteristics and outcomes according to the total number of lesions, and this number was used for our analysis. ${ }^{12}$ Lesion complexity was reported using the J-CTO score. ${ }^{20}$

\section{5 | Data synthesis and statistical analysis}

Statistical analysis was conducted using the Review Manager Software (Version 5.3.5. Copenhagen: The Nordic Cochrane Centre, the Cochrane Collaboration, 2014). Categorical variables were described as percentages while continuous variables were described as means with SD. Categorical variables were compared using Fisher's exact test or chi-square test, while continuous variables were compared using the two-sample $t$ test. Tests were two-tailed, and a $p$ value $\leq .05$ was considered statistically significant.

Odds ratios (ORs), and mean difference (MD) with 95\% confidence intervals (Cls) are presented as summary statistics. Cls were calculated at $95 \%$ level for overall estimates effect. Statistical heterogeneity was assessed by $\mathrm{I}^{2}$ statistics; $\mathrm{I}^{2}$ statistic $>50 \%$ was considered substantial, and $\mathrm{I}^{2}>75 \%$ was considered considerable. ${ }^{21}$ As a high degree of clinical and methodological heterogeneity was anticipated, we used the Der-Simonian and Laird random-effects and random-effects generic inverse variance methods to calculate $O R$ and $\mathrm{MD}$, respectively. ${ }^{22}$ Baseline characteristics, follow-up periods, and event rates were weighted according to sample size. Potential publication bias was assessed using the Egger's test through visual examination of the funnel plots. ${ }^{23}$

A subgroup test for statistical interaction was performed to assess whether the association between retrograde (vs. antegrade) procedures and outcomes differed when retrograde was used as a primary strategy (retrograde approach was the primary approach used in $>95 \%$ of the patients) versus only after failure of the antegrade approach. Sensitivity analysis was performed excluding lower quality studies as assessed by the Newcastle-Ottawa Scale. ${ }^{10}$

\section{3 | RESULTS}

\subsection{Characteristics of the included studies and quality assessment}

The study selection process is described in Figure S1. Twelve observational studies with a total of 10,240 patients $(10,363$ lesions) met our inclusion criteria. ${ }^{4,8,10-17,24,25}$ The characteristics of the included studies are described in Table 1. Patients were enrolled from 2005 to 2016. Three studies reported patients from North America, ${ }^{4,8,11}$ four from Europe, ${ }^{10,12,16,17}$ and five from Asia. ${ }^{13-15,24,25}$ The retrograde approach was used as the primary approach in two studies ${ }^{17,24}$; after the failure of antegrade approach in two studies ${ }^{10,16}$; and as a mix of both in the rest of the studies. ${ }^{4,8,11-15,25}$ The retrograde arm included 2,789 patients (2,816 lesions), while the antegrade arm included 7,451 patients (7,547 lesions).

Long-term outcomes were reported in four studies, including 2,269 patients who completed follow-up. , 13,15,17 $^{\text {The weighted mean }}$ follow-up duration was $48 \pm 31$ months. All studies met the inclusion criteria. Publication bias, as assessed by the Egger's test funnel plots is illustrated in Figures S2-S11. Bias assessment as per the NewcastleOttawa Scale for observational studies is shown in Table S2.

\subsection{Baseline characteristics of the included cohort}

The baseline clinical and angiographic characteristics for lesions and patients undergoing $\mathrm{CTO} \mathrm{PCl}$ using the retrograde versus an

TABLE 1 Baseline characteristics of the included studies

\begin{tabular}{|c|c|c|c|c|c|}
\hline Study & Study type & $\begin{array}{l}\text { Country, number } \\
\text { of centers }\end{array}$ & $\begin{array}{l}\text { Enrollment } \\
\text { dates }\end{array}$ & $\begin{array}{l}\text { Number of } \\
\text { patients/lesions }\end{array}$ & $\begin{array}{l}\text { Retrograde grade } \\
\text { approach (primary or after } \\
\text { antegrade approach failure) }\end{array}$ \\
\hline Galassi et al. 2011 & Observational & Europe, 16 & 2008-2009 & $1983 / 1983$ & $97.2 \%$ primary \\
\hline Michael et al. 2014 & Observational & USA, 1 & 2008-2011 & $193 / 193$ & $34 \%$ primary \\
\hline Werner et al. 2014 & Observational & Germany, 1 & 2006-2011 & $392 / 492$ & After failure of antegrade \\
\hline Karmpaliotis et al. 2016 & Observational & USA, 11 & $2012-2015$ & $1276 / 1301$ & $46 \%$ primary \\
\hline Lee et al. 2017 & Observational & Taiwan,1 & $2012-2013$ & $321 / 321$ & $40.2 \%$ primary \\
\hline Suzuki et al. 2017 & Observational & Japan, multi-center & 2014-2015 & $2596 / 2596$ & $100 \%$ primary \\
\hline Zivelonghi et al. 2018 & Observational & Belgium \& Netherlands, 8 & $2012-2015$ & $330 / 330$ & $100 \%$ primary \\
\hline
\end{tabular}


antegrade-only approach are summarized in Table S3. Patients in the retrograde arm had more prior Mls ( $43 \%$ vs. $35.2 \%, p<.001$ ), prior PCls $(69.7 \%$ vs. $41.7 \%, p<.001)$, and prior failed attempts $(43.7 \%$ vs. $19.9 \%, p<.001)$. Lesions treated with the retrograde approach were more likely to be in the right coronary artery (RCA) $(62.8 \%$ vs. $47.3 \%, p<.001)$, were longer $(35.2 \pm 13.6$ vs. $21.9 \pm 9 \mathrm{~mm}$, $p<.001)$ and had higher mean J-CTO score $(2.8 \pm 1.2$ vs. 1.9 $\pm 1.2, p<.001$ ).

\section{3 | Study endpoints}

\subsection{1 | In-hospital adverse events}

The retrograde and antegrade-only CTO PCI had similar in-hospital mortality $(0.5 \%$ vs. $0.21 \%$; OR $2.01,95 \% \mathrm{Cl} 0.91-4.43 ; p=.08$, $\left.\mathrm{I}^{2}=0 \%\right)$. Use of the retrograde approach was associated with higher incidence of $\mathrm{MI}(3.07 \%$ vs. $1.27 \%$; OR $2.37,95 \% \mathrm{Cl} 1.7-3.32$, $\left.p<.001 ; 1^{2}=0 \%\right)$, need for urgent pericardiocentesis $(1.07 \%$ vs. $0.42 \%$; OR $2.53,95 \% \mathrm{Cl} 1.41-4.51, p=.002, \mathrm{I}^{2}=0 \%$ ), and contrast-induced nephropathy $(3.38 \%$ vs. $1.57 \%$; OR $2.12,95 \% \mathrm{Cl}$ $\left.1.47-3.08 ; p<.001, I^{2}=0 \%\right)$. There was no difference in the need for urgent revascularization $(0.21 \%$ vs. $0.34 \%$; OR $0.82,95 \% \mathrm{Cl}$ $\left.0.30-2.25, p=.70 ; 1^{2}=0 \%\right)$ or cerebrovascular events $(0.44 \%$ vs. $0.19 \%$; OR $1.95,95 \% \mathrm{Cl} 0.87-4.38 ; p=.11, \mathrm{I}^{2}=0 \%$ ) (Figures $\mathrm{S} 12$ and S13).

\subsection{2 | Procedural characteristics}

Compared with antegrade $\mathrm{CTO} \mathrm{PCl}$, retrograde $\mathrm{CTO} \mathrm{PCl}$ was associated with lower procedure success rate $(80.9 \%$ vs. $87.4 \%$; OR for procedural failure $2.16,95 \% \mathrm{Cl} 1.71-2.73, p<.001, \mathrm{I}^{2}=63 \%$ ), longer duration (mean difference $61.52 \mathrm{~min}, 95 \% \mathrm{Cl}$ 50.57-72.48 min), $p<.001, \mathrm{I}^{2}=97 \%$ ), longer fluoroscopy time (mean difference $32.33 \mathrm{~min}, 95 \% \mathrm{Cl} 23.45-41.22 \mathrm{~min} ; p<.001, \mathrm{I}^{2}=99 \%$ ), and higher contrast volume (mean difference $76.73 \mathrm{~mL} ; 95 \% \mathrm{Cl} 50.9-96.55 \mathrm{~mL}$, $\left.p<.001, I^{2}=95 \%\right)$, (Figure S14).

\subsection{3 | Long-term outcomes}

During a mean follow-up duration of $48 \pm 31$ months, there was no difference in long-term mortality with retrograde versus antegrade procedures (13\% vs. $8.8 \%$; OR $1.79,95 \% \mathrm{Cl} 0.84-3.81, p=.13$, $\left.I^{2}=74 \%\right)$. The retrograde approach, however, was associated with higher risk of $\mathrm{MI}(5.6 \%$ vs. $2.6 \%$; OR 2.07, $95 \% \mathrm{Cl}: 1.10-3.88, p=.02$, $\mathrm{I}^{2}=0 \%$ ), TVR (32.3\% vs. $17.3 \%$; OR $1.92,95 \% \mathrm{Cl}: 1.49-2.46$ $p<.001, \mathrm{I}^{2}=0 \%$ ), and $\operatorname{TLR}(12.9 \%$ vs. $7.2 \%$; OR $2.08,95 \% \mathrm{Cl}$ : 1.33-3.25, $p=.001, \mathrm{I}^{2}=0 \%$; Figure $\mathrm{S} 15$ ).

\subsection{Subgroup and sensitivity analyses}

On subgroup analysis, the association between retrograde $\mathrm{PCl}$ and outcomes was not significantly different based on whether retrograde was performed as the primary approach versus after a failed antegrade crossing attempt: in-hospital mortality ( $p$ interaction $=.28$ ), procedural success ( $p$ interaction $=.68$ ), or the need for urgent pericardiocentesis ( $p$ interaction $=.30 ; p$ interaction $=.28$ ); Figure S16). With the exclusion of one lower quality study, ${ }^{10}$ there was no difference in the outcomes after both approaches.

The summary of the study results is illustrated in Figure 1.

\section{4 | DISCUSSION}

To the best of our knowledge, this is the first meta-analysis of both in-hospital and long-term outcomes with retrograde versus antegrade-only crossing techniques in CTO PCI. The main findings can be summarized as follows: (a) patients who underwent retrograde CTO $\mathrm{PCl}$ had more technically complex lesions, a higher prevalence of prior $\mathrm{PCl}$ and $\mathrm{CABG}$, and more comorbidities; as a result, the retrograde procedures were longer requiring more contrast and fluoroscopy; (b) the retrograde approach was associated with higher in-hospital MI, urgent pericardiocentesis, and contrast-induced nephropathy compared with the antegrade approach, but no difference in in-hospital mortality, urgent revascularization, or cerebrovascular events; and (c) the retrograde approach was associated with higher long-term incidence of $\mathrm{MI}$, TLR, and TVR but not mortality.

Several observational studies ${ }^{26-31}$ and two RCTs ${ }^{32,33}$ have reported that successful CTO $\mathrm{PCl}$ is associated with improvement in the quality of life, reduced need for CABG, improved left ventricular (LV) function, and LV reverse remodeling compared with failed revascularization. The retrograde approach is currently an essential tool for achieving high success rates, especially in complex lesions where the antegrade approach is not technically feasible or fails. ${ }^{34}$ According to the hybrid algorithm, proximal cap ambiguity, poor-quality distal vessel and the presence of interventional collaterals favor the use of the retrograde approach. ${ }^{35}$ In a multicenter CTO PCI registry, overall technical success was $86 \%$, and the retrograde approach was used in $34.9 \%$ of the successful cases. ${ }^{5}$ The higher success rate with the retrograde approach is likely related to the histopathological features of the distal СТО cap which is more likely to be tapered and less fibrocalcific and therefore less resistant to guidewire advancement. ${ }^{36,37}$

In our analysis, the retrograde procedures were longer requiring more contrast and fluoroscopy and were associated with more in-hospital adverse events. Coronary perforation (Ellis classification grade III) with subsequent need for pericardiocentesis has been associated with high rates of long-term major adverse cardiac events. ${ }^{38}$ Peri-procedural MI, which is more likely to occur with the retrograde approach, likely due to the prolonged obstruction of collateral channels by the retrograde wire and microcatheters, has also been associated with worse long-term outcomes and higher mortality in some but not all studies. ${ }^{16,39,40}$ Most of these CTOs, however, could not have been revascularized by an antegrade-only approach and some of the complications attributed to the retrograde approach may have occurred during antegrade crossing attempts. Moreover, some studies in our analysis included patients from 2005 , which was early in the learning curve of the retrograde technique. 


\section{Outcomes with retrograde vs. antegrade approach in chronic total occlusion percutaneous coronary interventions}

Meta-analysis of twelve observational studies including 10,240 patients $(10,363$ lesions)
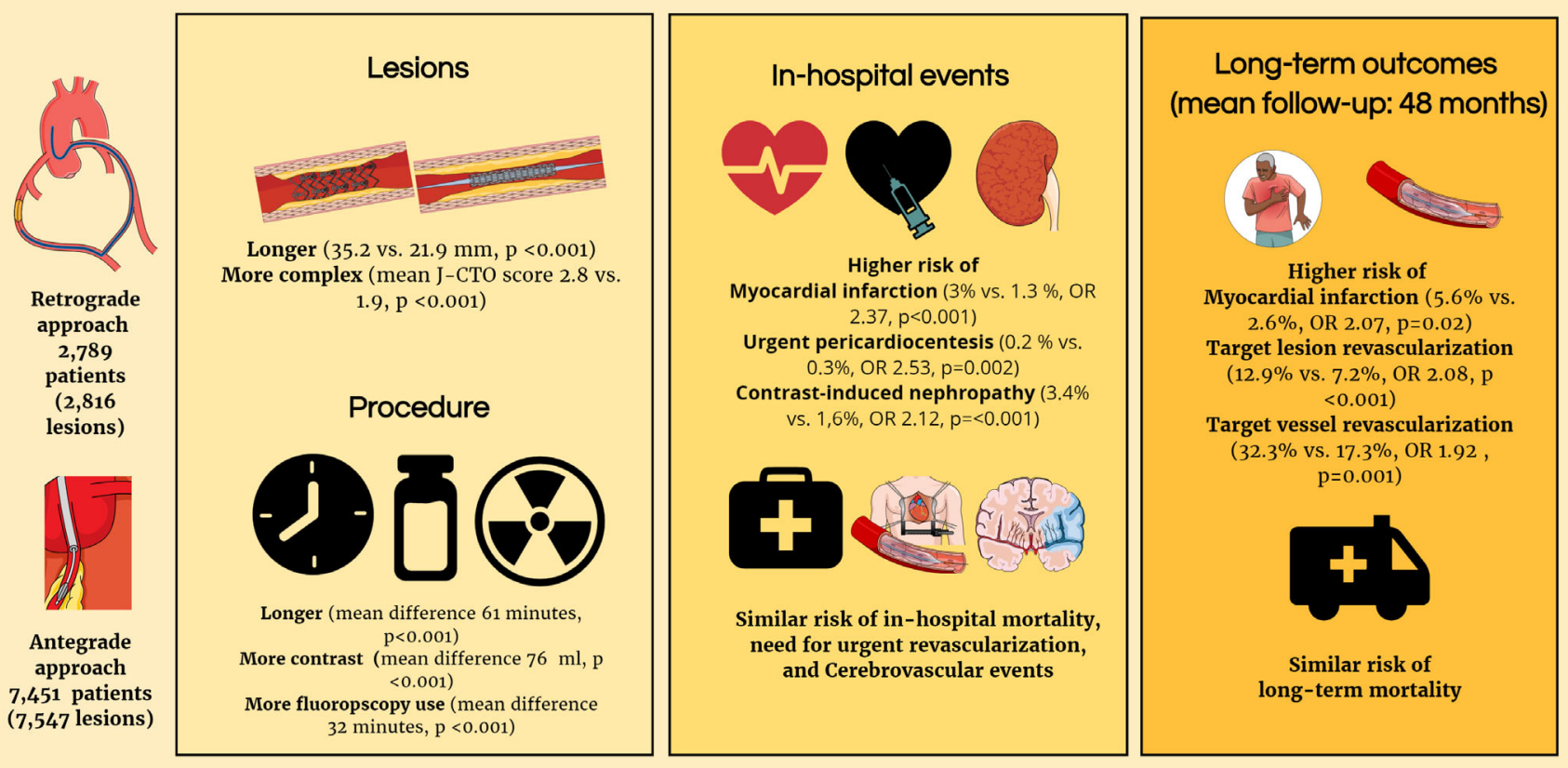

FIGURE 1 Summary of the study results [Color figure can be viewed at wileyonlinelibrary.com]

Similar to previous reports ${ }^{7,41}$ in our study retrograde CTO $\mathrm{PCI}$ was associated with more TLR, TVR, and MI as compared with antegrade-only CTO PCI during a mean follow-up of 4 years. Retrograde $\mathrm{PCl}$ is usually performed in more complex anatomy and might lead to implantation of longer and smaller-caliber stents, which in turn is associated with a higher risk of restenosis. ${ }^{42}$ Moreover, dissection and re-entry techniques, which are frequently used in the retrograde approach, may increase restenosis rates. ${ }^{43,44}$

The majority of patients in the retrograde group might have failed revascularization leading to subsequent worse outcomes, and a higher number of lesions in the retrograde group had already failed prior attempts rendering the retrograde approach the final option for successful revascularization. It possible that the worse outcomes with the retrograde approach are related to higher patient and lesion complexity and not the crossing strategy per se. Nevertheless, the retrograde approach should only be used when the perceived benefits outweigh the potential risks. Performance of retrograde CTO PCl by experienced operators who can identify and treat complications early and are attentive to the need for stent optimization, ${ }^{45}$ as well as using approaches that help reduce complications like the radial approach, ${ }^{46}$ could improve the outcomes of retrograde CTO PCI.

\section{1 | Limitations}

Our study has limitations. First, only observational studies compared antegrade and retrograde CTO PCls, which are subject to selection bias. Second, there was a high degree of heterogeneity between the studies (e.g., in the definition of success and periprocedural MI). Third, the details of the crossing techniques and the collaterals used for retrograde approach were not consistently reported in all studies and could not be used for further analysis. Fourth, the differential outcomes based on J-CTO components (e.g., calcification, occlusion length) were not consistently reported and, therefore, could not be reported. Finally, the included studies did not report the adjusted odds ratios. Thus, despite being the optimal statistical method, we could not use the pooled adjusted OR to confirm our results.

\section{5 | CONCLUSION}

Compared with antegrade $\mathrm{CTO} \mathrm{PCl}$, the retrograde approach is attempted in more complex lesions and is associated with a higher risk for acute and long-term complications. Judicious and skillful application of the retrograde approach remains a pillar of contemporary CTO PCl.

\section{DISCLOSURE OF INTERESTS}

Michael Megaly, Abdelrahman Ali, Marwan Saad, Mohamed Omer, losif Xenogiannis, Juan J. Russo, Masahisa Yamane, Roberto Garbo, Andrea Gagnor, Imre Ungi, Ashish Pershad, Jaroslaw Wojcik, Georgios Sianos, Alfredo R. Galassi: nothing to disclose. Gerald Werner: speaker honoraria for Asahi Intecc, Abbott Vascular, Biosensors, and Terumo; 
and has served as the principal investigator of a randomized trial on the benefit of СTO $\mathrm{PCl}$ versus medical therapy conducted by the EURO CTO Club, sponsored by Asahi Intecc and Biosensors. Dimitri Karmpaliotis: speaker honoraria from Abbott Vascular, Medtronic, Boston Scientific, and Vascular Solutions. Stephane Rinfret: Consultant, Boston Scientific, Abiomed, Abbott Vascular, and Soundbite Medical. Santiago Garcia: consultant for Surmodics, Osprey Medical, Medtronic, Edwards Lifesciences, and Abbott. Dr. Garcia has received grant support from Edwards Lifesciences and the VA Office of Research and Development. Kambis Mashayekhi: Consulting/ speaker/proctoring honoraria from Abbott Vascular, Ashai Intecc, AstraZeneca, Biotronik, Boston Scientific, Cardinal Health, Daiichi Sankyo, Medtronic, Teleflex, Terumo. M. Nicholas Burke: Consulting and speaker honoraria from Opsens Medical. Shareholder, Egg Medical and MHI Ventures. Emmanouil Brilakis: consulting/speaker honoraria from Abbott Vascular, American Heart Association (associate editor Circulation), Biotronik, Boston Scientific, Cardiovascular Innovations Foundation (Board of Directors), CSI, Elsevier, GE Healthcare, InfraRedx, Medtronic, Siemens, and Teleflex; research support from Regeneron and Siemens. Shareholder: MHI Ventures.

\section{ORCID}

Michael Megaly (D) https://orcid.org/0000-0003-3176-6677

Marwan Saad (D) https://orcid.org/0000-0002-2280-8030

losif Xenogiannis (D) https://orcid.org/0000-0002-5004-6635

Gerald S. Werner (D) https://orcid.org/0000-0002-6011-0135

Stephane Rinfret (D) https://orcid.org/0000-0003-1847-1583

Ashish Pershad (D) https://orcid.org/0000-0002-6424-4341

Santiago Garcia (D) https://orcid.org/0000-0003-3715-8082

Emmanouil S. Brilakis (D) https://orcid.org/0000-0001-9416-9701

\section{REFERENCES}

1. Serruys $P$, Hamburger J, Fajadet $J$, et al. Total occlusion trial with angioplasty by using laser guidewire. TOTAL Trial EurHeart J. 2000; 21(21):1797-1805.

2. Joyal D, Afilalo J, Rinfret S. Effectiveness of recanalization of chronic total occlusions: a systematic review and meta-analysis. Am Heart J. 2010;160(1):179-187.

3. Maeremans J, Walsh S, Knaapen P, et al. The hybrid algorithm for treating chronic total occlusions in Europe: the RECHARGE registry. J Am Coll Cardiol. 2016;68(18):1958-1970.

4. Karmpaliotis D, Karatasakis A, Alaswad K, et al. Outcomes with the use of the retrograde approach for coronary chronic total occlusion interventions in a contemporary multicenter US registry. Circ Cardiovasc Interv. 2016;9(6):e003434.

5. Sapontis J, Salisbury AC, Yeh RW, et al. Early procedural and health status outcomes after chronic total occlusion angioplasty: a report from the OPEN-CTO registry (outcomes, patient health status, and efficiency in chronic total occlusion hybrid procedures). J Am Coll Cardiol Intv. 2017;10(15):1523-1534.

6. Yamane $M$, Muto $M$, Matsubara $T$, et al. Contemporary retrograde approach for the recanalisation of coronary chronic total occlusion: on behalf of the Japanese Retrograde Summit Group. Eurolntervention. 2013;9(1):102-109.
7. Galassi AR, Sianos G, Werner GS, et al. Retrograde recanalization of chronic total occlusions in Europe: procedural, in-hospital, and longterm outcomes from the multicenter ERCTO registry. J Am Coll Cardiol. 2015;65(22):2388-2400.

8. Michael TT, Mogabgab O, Alomar M, et al. Long-term outcomes of successful chronic total occlusion percutaneous coronary interventions using the antegrade and retrograde approach. J Interv Cardiol. 2014;27(5):465-471.

9. El Sabbagh A, Patel VG, Jeroudi OM, et al. Angiographic success and procedural complications in patients undergoing retrograde percutaneous coronary chronic total occlusion interventions: a weighted meta-analysis of 3482 patients from 26 studies. Int J Cardiol. 2014; 174(2):243-248.

10. Bijuklic K, Schwencke C, Schofer J. Long-term MACCE rate after retrograde compared to Antegrade recanalization of chronic total coronary occlusions. J Health Med Inform. 2016;7(224):2.

11. Dautov R, Manh Nguyen C, Altisent O, Gibrat C, Rinfret S. Recanalization of chronic total occlusions in patients with previous coronary bypass surgery and consideration of retrograde access via saphenous vein grafts. Circ Cardiovasc Interv. 2016;9(7):e003515.

12. Galassi AR, Tomasello SD, Reifart N, et al. In-hospital outcomes of percutaneous coronary intervention in patients with chronic total occlusion: insights from the ERCTO (European Registry of Chronic Total Occlusion) registry. Eurolntervention. 2011;7(4):472-479.

13. Kwon O, Lee PH, Lee S-W, et al. Retrograde approach for percutaneous recanalization of coronary chronic total occlusions; contribution to clinical practice and its long-term results. Eurolntervention. 2019; 15(4):e354-e361.

14. Lee $\mathrm{C}-\mathrm{K}$, Chen $\mathrm{Y}-\mathrm{H}$, Lin M-S, et al. Retrograde approach is as effective and safe as antegrade approach in contemporary percutaneous coronary intervention for chronic total occlusion: a Taiwan single-center registry study. Acta Cardiol Sin. 2017;33(1):20-27.

15. Tanaka $\mathrm{H}$, Ohya $\mathrm{M}$, Kubo $\mathrm{S}$, et al. Impact of retrograde approach on long-term clinical outcomes of patients undergoing coronary chronic total occlusion interventions. Eurolntervention. 2018;14(11): e1183-e1191.

16. Werner GS, Coenen A, Tischer K-H. Periprocedural ischaemia during recanalisation of chronic total coronary occlusions: the influence of the transcollateral retrograde approach. Eurolntervention. 2014;10 (7):799-805.

17. Zivelonghi $\mathrm{C}$, van Andel $\mathrm{M}$, Venturi $\mathrm{G}$, et al. Angiographic and clinical outcomes of antegrade versus retrograde techniques for chronic total occlusion revascularizations: insights from the PRISON IV trial. Catheter Cardiovasc Interv. 2019;93(2):E81-E89.

18. Stroup DF, Berlin JA, Morton SC, Olkin I, Williamson GD, Rennie D, Moher D, Becker BJ, Sipe TA, Thacker SB. Meta-analysis of observational studies in epidemiology: a proposal for reporting. JAMA 2000; 283(15):2008-2012.

19. Wells G, Shea B, O'connell D, Peterson J, Welch V, Losos M, et al. The Newcastle-Ottawa Scale (NOS) for Assessing the Quality of Nonrandomised Studies in Meta-Analyses. 2011. www.ohri.ca/programs/ clinical_epidemiology/oxford.htm.

20. Morino $\mathrm{Y}$, Abe $M$, Morimoto $\mathrm{T}$, et al. Predicting successful guidewire crossing through chronic total occlusion of native coronary lesions within 30 minutes: the J-CTO (Multicenter CTO Registry in Japan) score as a difficulty grading and time assessment tool. J Am Coll Cardiol Intv. 2011;4(2):213-221.

21. Higgins JP, Thompson SG, Deeks JJ, Altman DG. Measuring inconsistency in meta-analyses. BMJ. 2003;327(7414):557-560.

22. Rao G, Lopez-Jimenez F, Boyd J, et al. Methodological standards for meta-analyses and qualitative systematic reviews of cardiac prevention and treatment studies: a scientific statement from the American Heart Association. Circulation. 2017;136(10):e172-e194.

23. Egger M, Smith GD, Schneider M, Minder C. Bias in meta-analysis detected by a simple, graphical test. BMJ. 1997;315(7109):629-634. 
24. Suzuki Y, Tsuchikane E, Katoh O, et al. Outcomes of percutaneous coronary interventions for chronic total occlusion performed by highly experienced Japanese specialists: the first report from the Japanese CTO-PCl expert registry. J Am Coll Cardiol Intv. 2017;10(21): 2144-2154.

25. Wu EB, Tsuchikane E, Ge L, et al. Retrograde versus Antegrade approach for coronary chronic Total occlusion in an Algorithm-Driven Contemporary Asia-Pacific Multicenter Registry: comparison of outcomes. Heart Lung Circ. 2020;29(6):894-903.

26. Borgia F, Viceconte N, Ali O, et al. Improved cardiac survival, freedom from MACE and angina-related quality of life after successful percutaneous recanalization of coronary artery chronic total occlusions. Int J Cardiol. 2012;161(1):31-38.

27. Yamamoto $E$, Natsuaki $M$, Morimoto $T$, et al. Long-term outcomes after percutaneous coronary intervention for chronic total occlusion (from the CREDO-Kyoto registry cohort-2). Am J Cardiol. 2013;112 (6):767-774.

28. Khan MF, Wendel CS, Thai HM, Movahed MR. Effects of percutaneous revascularization of chronic total occlusions on clinical outcomes: a meta-analysis comparing successful versus failed percutaneous intervention for chronic total occlusion. Catheter Cardiovasc Interv. 2013;82(1):95-107.

29. Megaly M, Saad M, Tajti P, et al. Meta-analysis of the impact of successful chronic total occlusion percutaneous coronary intervention on left ventricular systolic function and reverse remodeling. J Interv Cardiol. 2018;31(5):562-571.

30. Cheng AS, Selvanayagam JB, Jerosch-Herold M, et al. Percutaneous treatment of chronic total coronary occlusions improves regional hyperemic myocardial blood flow and contractility: insights from quantitative cardiovascular magnetic resonance imaging. J Am Coll Cardiol Intv. 2008;1(1):44-53.

31. Galassi AR, Boukhris M, Toma A, et al. Others. Percutaneous coronary intervention of chronic total occlusions in patients with low left ventricular ejection fraction. JACC Cardiovasc Interv. 2017;10(21):21582170.

32. Werner GS, Martin-Yuste V, Hildick-Smith D, et al. A randomized multicentre trial to compare revascularization with optimal medical therapy for the treatment of chronic total coronary occlusions. Eur Heart J. 2018;39(26):2484-2493.

33. Elias J, van Dongen IM, Råmunddal $T$, et al. Long-term impact of chronic total occlusion recanalisation in patients with ST-elevation myocardial infarction. Heart. 2018;104(17):1432-1438.

34. Tajti P, Karmpaliotis D, Alaswad K, et al. The hybrid approach to chronic total occlusion percutaneous coronary intervention: update from the PROGRESS CTO registry. J Am Coll Cardiol Intv. 2018;11 (14):1325-1335.

35. Brilakis ES, Grantham JA, Rinfret S, et al. A percutaneous treatment algorithm for crossing coronary chronic total occlusions. J Am Coll Cardiol Intv. 2012;5(4):367-379.

36. Tran P, Phan H, Shah SR, Latif F, Nguyen T. Applied pathology for interventions of coronary chronic total occlusion. Curr Cardiol Rev. 2015;11(4):273-276.
37. Irving J. СTO pathophysiology: how does this affect management? Curr Cardiol Rev. 2014;10(2):99-107.

38. Al-Lamee R, lelasi A, Latib A, et al. Incidence, predictors, management, immediate and long-term outcomes following grade III coronary perforation. J Am Coll Cardiol Intv. 2011;4(1):87-95.

39. Lee S-W, Lee PH, Kang SH, et al. Determinants and prognostic significance of periprocedural myocardial injury in patients with successful percutaneous chronic total occlusion interventions. J Am Coll Cardiol Intv. 2016;9(21):2220-2228.

40. Toma A, Stahli BE, Gebhard C, et al. Clinical implications of periprocedural myocardial injury in patients undergoing percutaneous coronary intervention for chronic total occlusion: role of antegrade and retrograde crossing techniques. Eurolntervention. 2018;13(17): 2051-2059.

41. Maeremans J, Avran A, Walsh S, et al. One-year clinical outcomes of the hybrid CTO revascularization strategy after hospital discharge: a subanalysis of the multicenter RECHARGE registry. J Invasive Cardiol. 2018;30(2):62-70.

42. Maluenda G, Ben-Dor I, Gaglia MA Jr, et al. Clinical outcomes and treatment after drug-eluting stent failure: the absence of traditional risk factors for in-stent restenosis. Circ Cardiovasc Interv. 2012;5(1): 12-19.

43. Michael TT, Papayannis AC, Banerjee S, Brilakis ES. Subintimal dissection/reentry strategies in coronary chronic total occlusion interventions. Circ Cardiovasc Interv. 2012;5(5): 729-738.

44. Valenti R, Vergara R, Migliorini A, et al. Predictors of reocclusion after successful drug-eluting stent-supported percutaneous coronary intervention of chronic total occlusion. J Am Coll Cardiol. 2013;61(5): 545-550.

45. Brilakis ES, Mashayekhi K, Tsuchikane E, et al. Guiding principles for chronic total occlusion percutaneous coronary intervention: a global expert consensus document. Circulation. 2019;140(5): 420-433.

46. Megaly $M$, Karatasakis A, Abraham B, et al. Radial versus femoral access in chronic total occlusion percutaneous coronary intervention: a systematic review and meta-analysis. Circ Cardiovasc Interv. 2019; 12(6):e007778.

\section{SUPPORTING INFORMATION}

Additional supporting information may be found online in the Supporting Information section at the end of this article.

How to cite this article: Megaly M, Ali A, Saad M, et al. Outcomes with retrograde versus antegrade chronic total occlusion revascularization. Catheter Cardiovasc Interv. 2020; 96:1037-1043. https://doi.org/10.1002/ccd.28616 